\title{
Manejo da irrigação e fertirrigação com nitrogênio sobre as características químicas da videira 'Niágara Rosada'
}

\author{
Irrigation management and fertirrigation with nitrogen on the chemical characteristics of the \\ grapevine 'Niagara Rosada'
}

\author{
Cristiani Campos Martins Busato ${ }^{\mathrm{I} *}$ Antonio Alves Soares ${ }^{\mathrm{II}}$ Gilberto Chohaku Sediyama $^{\mathrm{I}}$ \\ Sérgio Yoshimitsu Motoike ${ }^{\mathrm{III}}$ Edvaldo Fialho dos Reis ${ }^{\mathrm{IV}}$
}

\section{RESUMO}

\begin{abstract}
A qualidade da uva pode responder ao manejo da irrigação e ao ajuste da adubação nitrogenada. Assim, este trabalho teve como objetivo estudar o efeito do manejo de irrigação e doses de nitrogênio sobre a qualidade da uva 'Niagara Rosada' no município de Colatina-ES. Foram avaliadas três doses de nitrogênio, aplicadas via fertirrigação:

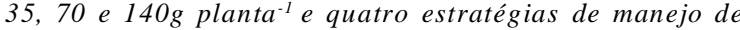
irrigação. No início do experimento até a fase de maturação das bagas, todos os tratamentos receberam a mesma lâmina de irrigação, elevando-se a umidade do solo à capacidade de campo $(M 1=100 \%)$. Após este período, foram avaliados mais três estratégias de manejo de irrigação: $M 2=67 \%, M 3=33 \% e$ M4=0\% da lâmina correspondente ao tratamento M1. Foram avaliados os teores de sólidos solúveis (SS), pH e acidez titulável (AT). Os resultados indicaram que os tratamentos sob déficit hídrico (M3 e M4), nas doses de 70 e $140 \mathrm{~g}_{\text {planta-1 }^{-1}}$ apresentaram maiores teores de SS e pH das bagas e diminuição dos valores de AT.
\end{abstract}

Palavras-chave: Vitis, nutrição mineral, estresse hídrico.

\section{ABSTRACT}

The quality of the grape can respond to irrigation and $N$ fertilization adjustment. So, this research aimed to study the effect of irrigation management and doses of nitrogen on 'Niagara Rosada' grape quality in Colatina (ES) municipality. It was evaluated three doses of nitrogen applied by fertigation: 35, 70 and $140 \mathrm{~g}_{\text {plant }}{ }^{-1}$ and four strategies of irrigation management. From the beginning of the experiment until the stage of maturation, all treatments received the same water depth, increasing soil moisture at field capacity $(M 1=100 \%)$.
After this period, it was evaluated three strategies for irrigation management: $M 2=67 \%, M 3=33 \%$ and $M 4=0 \%$ of the depth corresponding to the M1 treatment. It was appraised the content of soluble solids (SS), $p H$ and acidity (AT). The results indicated that the treatments under water stress, in the rates of 70 and $140 \mathrm{~g}$ plant $^{1}$ presented larger rates of SS and $\mathrm{pH}$ of the berries and decreasing values of AT.

Key words: Vitis, mineral nutrition, water stress.

\section{INTRODUÇÃO}

A 'Niágara Rosada' é a principal cultivar de uva para mesa produzida no Estado do Espírito Santo. O município de Colatina caracteriza-se pela irregularidade das chuvas e ocorrência de elevadas temperaturas, sendo o uso da irrigação indispensável. A irrigação teve um avanço considerável nas últimas décadas, tanto no que diz respeito ao aprimoramento de novos métodos de distribuir água ao solo e às culturas, quanto no incremento de novas áreas irrigadas. Dentre as vantagens da irrigação, está aquela que possibilita utilizar o sistema como meio condutor e distribuidor de produtos químicos, como fertilizantes, simultaneamente com a água de irrigação (BERNARDO et al., 2008). Essa prática, conhecida como fertirrigação, adequa-se principalmente à irrigação localizada.

\footnotetext{
Instituto Federal do Espírito Santo (IFES), Campus Itapina, Rod. BR 259, Km 70, 29709-910, Colatina, ES, Brasil.

E-mail: cristiani.busato@ifes.edu.br.*Autor para correspondência.

I"Departamento de Engenharia Agrícola, Universidade Federal de Viçosa (UFV), Viçosa, MG, Brasil.

IIIDepartamento de Fitotecnia, UFV, Viçosa, MG, Brasil.

${ }^{\mathrm{IV}}$ Centro de Ciências Agrárias, Universidade Federal do Espírito Santo (CCAUFES), Alegre, ES, Brasil.
} 
O aspecto nutricional é outro fator de fundamental importância, cujo manejo deve ser ajustado à cada fase específica do ciclo da cultura. A adubação nitrogenada tem efeito na produção e nas características químicas da uva e do seu mosto, afetando os teores de sólidos solúveis, de $\mathrm{pH}$, de acidez titulável, de ácidos orgânicos e de nutrientes (BELL \& ROBSON, 1999). De acordo com FERREYRA et al. (2004), em viticultura, devem-se adotar estratégias de manejo em relação à disponibilidade da água no solo e ajuste da adubação para direcionar os recursos da planta, visando à qualidade da produção.

Sob níveis não restritivos de água no solo, o crescimento vegetativo é excessivo e compete com as bagas por assimilados. Por outro lado, um déficit hídrico muito severo pode afetar negativamente a produtividade e a qualidade da uva. Com relação à composição química da baga, não havendo excesso de precipitação pluvial, quanto mais elevada for a temperatura da região de cultivo, dentro dos limites críticos, o clima contribuirá para uma concentração maior de açúcar e menor de ácido málico, favorecendo as produções de uva para mesa, passas e vinhos doces, conforme verificado nos trabalhos de TEIXEIRA et al. (2002), no Estado da Bahia.

Na fase de veraison ou início da maturação dos frutos, há aproximadamente 60 dias após o florescimento, ocorre a mudança de cor e de textura da baga. Um correto manejo de irrigação aplicado nesta fase poderá aumentar o acúmulo de açúcares nas bagas.

Este trabalho teve como objetivo estudar o efeito de quatro estratégias de manejo da irrigação e três doses de nitrogênio, aplicadas via fertirrigação, sobre a qualidade da uva cultivar 'Niágara Rosada', cultivada no município de Colatina-ES.

\section{MATERIAL E MÉTODOS}

A pesquisa foi realizada no Instituto Federal do Espírito Santo - IFES, Campus Itapina, no município de Colatina-ES, situada a $19^{\circ} 32^{\prime} 22^{\prime \prime} \mathrm{S}$ e $40^{\circ} 37^{\prime} 50^{\prime \prime} \mathrm{O}$ e altitude de $71 \mathrm{~m}$. O clima do local é Tropical Aw, segundo a classificação climática de Köppen. Os dados meteorológicos foram obtidos na estação climatológica automática existente no IFES.

O solo utilizado é classificado como Latossolo Vermelho-Amarelo distrófico (EMBRAPA, 2006) e suas características químicas (Tabela 1) foram determinadas pela análise de amostras retiradas nas camadas de 0-20, 20-40 e 40-60 cm de profundidade, realizadas antes do início do experimento.

O experimento foi realizado com a cultivar de videira 'Niágara Rosada', no sistema de latada, com espaçamento 3,0m entre plantas e 2,0m entre linhas,

Tabela 1 - Características químicas do solo do experimento, nas camadas 0-20, 20-40 e 40-60cm de profundidade. Colatina, ES. 2009.

\begin{tabular}{|c|c|c|c|}
\hline \multirow{2}{*}{ Características químicas } & \multicolumn{3}{|c|}{ 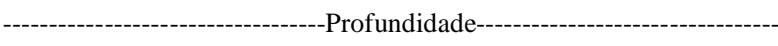 } \\
\hline & $0-20$ & $20-40$ & $40-60$ \\
\hline pH em água $-1: 2,5$ & 5,82 & 5,70 & 5,50 \\
\hline Matéria orgânica $(\mathrm{MO})\left(\mathrm{dag} \mathrm{kg}^{-1}\right)^{1}$ & 1,66 & 0,88 & 1,15 \\
\hline $\mathrm{P}(\mathrm{mg} \mathrm{dm})^{-3}{ }^{2}$ & 4,70 & 3,00 & 2,00 \\
\hline $\left.\mathrm{K}(\mathrm{mg} \mathrm{dm})^{-3}\right)^{2}$ & 209,00 & 273,00 & 249,00 \\
\hline $\mathrm{Ca}^{2+}\left(\mathrm{cmol}_{\mathrm{c}} \mathrm{dm}^{-3}\right)^{3}$ & 2,48 & 3,09 & 3,54 \\
\hline $\mathrm{Mg}^{2+}\left(\mathrm{cmol}_{\mathrm{c}} \mathrm{dm}^{-3}\right)^{3}$ & 1,29 & 1,36 & 0,89 \\
\hline Acidez trocável $\left(\mathrm{Al}^{3+}\right)\left(\mathrm{cmol}_{\mathrm{c}} \mathrm{dm}^{-3}\right)^{3}$ & 0,00 & 0,00 & 0,05 \\
\hline Acidez potencial $(\mathrm{H}+\mathrm{Al})\left(\mathrm{cmol}_{\mathrm{c}} \mathrm{dm}^{-3}\right)^{4}$ & 5,00 & 2,09 & 2,42 \\
\hline Soma de bases (SB) $\left(\mathrm{cmol}_{\mathrm{c}} \mathrm{dm}^{-3}\right)$ & 4,34 & 5,15 & 5,07 \\
\hline CTC efetiva $(\mathrm{t})\left(\mathrm{cmol}_{\mathrm{c}} \mathrm{dm}^{-3}\right)$ & 4,44 & 5,15 & 5,12 \\
\hline CTC a pH 7,0 (T) $\left(\mathrm{cmol}_{\mathrm{c}} \mathrm{dm}^{-3}\right)$ & 9,34 & 7,24 & 7,49 \\
\hline Saturação de Alumínio (m) (\%) & 2,30 & 0,00 & 1,00 \\
\hline Saturação de bases (V) (\%) & 46,5 & 71,1 & 67,7 \\
\hline \multicolumn{4}{|l|}{ Micronutrientes: } \\
\hline $\left.\mathrm{Zn}(\mathrm{mg} \mathrm{dm})^{-3}\right)^{2}$ & 4,48 & & \\
\hline $\mathrm{Fe}\left(\mathrm{mg} \mathrm{dm}^{-3}\right)^{2}$ & 20,2 & & \\
\hline $\operatorname{Mn}\left(\mathrm{mg} \mathrm{dm}^{-3}\right)^{2}$ & 22,4 & & \\
\hline $\mathrm{Cu}\left(\mathrm{mg} \mathrm{dm}^{-3}\right)^{2}$ & 2,05 & & \\
\hline $\mathrm{B}\left(\mathrm{mg} \mathrm{dm}^{-3}\right)^{5}$ & 0,0 & & \\
\hline
\end{tabular}

${ }^{1}$ Mat. Org. $(\mathrm{MO})=\mathrm{C}$. Org x $1,724-$ Walkley-Black; ${ }^{2}$ Extrator Mehlich $1 ;{ }^{3}$ Extrator $\mathrm{KCl} 1$ mol.L ${ }^{-1} ;{ }^{4}$ Extrator Acetato de cálcio 0,5 mol.L ${ }^{-1}$ $\mathrm{pH} 7,0 ;{ }^{5}$ Extrator água quente.

Ciência Rural, v.41, n.7, jul, 2011. 
com idade de quatro anos, em uma área de $480 \mathrm{~m}^{2}$. A adubação de fundação foi realizada com a aplicação de $600 \mathrm{~g}$ planta $^{-1}$ do adubo superfosfato simples, $60 \mathrm{~g}$ planta $^{-1}$ de cloreto de potássio e $3 \mathrm{~L}$ planta ${ }^{-1}$ de húmus de minhoca. A área experimental era formada por quatro fileiras de plantas, contendo 20 plantas em cada fileira. As plantas foram cultivadas com o Sistema de Irrigação Localizada com emissor Microjet. Apresenta vazão nominal de $14 \mathrm{~L} \mathrm{~h}^{-1}$, à pressão de $1,0 \mathrm{kgf} \mathrm{cm}^{-2}$. A montagem do sistema foi realizada diretamente na linha de polietileno por engate tipo bisel, utilizando-se espaçamento de $2 \mathrm{~m}$.

O manejo da irrigação foi realizado com base na umidade do solo, utilizando-se uma bateria de três tensiômetros instalados a 0-20, 20-40 e 40-60 cm de profundidade a uma distância de $50 \mathrm{~cm}$ das plantas, durante todo o período do experimento. $\mathrm{O}$ turno de rega foi fixado em quatro dias. A partir da leitura de tensão observada no tensiômetro instalado na parcela que recebia $100 \%$ da irrigação, calculava-se a umidade do solo de acordo com a curva de retenção. A lâmina de irrigação era determinada pelo valor de umidade referente à tensão lida no tensiômetro, subtraída da umidade correspondente à capacidade de campo. Utilizou-se a profundidade de $60 \mathrm{~cm}$ para o cálculo da lâmina de água. Esse cálculo fornecia a lâmina a ser aplicada por irrigação para o tratamento M1 $=100 \%$, ou seja, nesse tratamento, a umidade do solo variou do valor de umidade estimado indiretamente pelo tensiômetro à capacidade de campo, repondo todo o déficit hídrico.

Os níveis de manejo da irrigação em cada parcela de adubação nitrogenada foram assim denominados: Nível 1 (M1): reposição de $100 \%$ da lâmina de irrigação (controle); Nível 2 (M2): reposição de 67\% da lâmina de irrigação; Nível 3 (M3): reposição de 33\% da lâmina de irrigação e; Nível 4 (M4): sem irrigação. No início do experimento, todos os níveis receberam uma irrigação para elevar a umidade do solo à capacidade de campo. A partir daí, o monitoramento da água no solo foi feito até o final da colheita em 2009, com o uso dos tensiômetros. Esse manejo foi adotado para todos os tratamentos até 60 dias após o florescimento.

Após este período, na fase de veraison ou no início da maturação dos frutos, foram avaliados mais três estratégias de manejos de irrigação, ou seja, nos tratamentos M2, M3 e M4, a umidade do solo não foi elevada para a condição de capacidade de campo e a cultura foi submetida a um estresse hídrico que variou conforme os tratamentos.

Foram avaliadas três doses de nitrogênio, aplicadas via fertirrigação: 35,70 e $140 \mathrm{~g}_{\text {planta }}{ }^{-1}$. Utilizou-se como fonte de nitrogênio a uréia, que continha $45 \%$ de N, dissolvida em 100L de água em um reservatório de amianto e fornecida às plantas, utilizando-se um injetor de fertilizantes tipo Venturi.

A recomendação de adubação do nitrogênio (N) foi parcelada em três aplicações: 10 dias após o início da brotação (ramo com aproximadamente $30 \mathrm{~cm}$ ), foram aplicados $50 \%$ da recomendação do $\mathrm{N}$ em cada parcela; na fase de abertura das flores (aproximadamente 30 dias após o início da brotação), foram aplicados $25 \%$ de recomendação do $\mathrm{N}$ em cada parcela e; na fase de frutos do tamanho de ervilha, foram aplicados os $25 \%$ restantes de cada parcela.

Os tratos culturais e fitossanitários foram efetuados sempre que necessário, segundo as recomendações técnicas da cultura (SÔNEGO et al., 2004).

As características químicas foram avaliadas por uma amostragem aleatória de 20 bagas por tratamento, usando-se seis repetições. As bagas foram amassadas em copos plásticos para a obtenção do mosto. $\mathrm{O}$ pH foi obtido por leitura direta ao se mergulhar no mosto o peagâmetro previamente calibrado em solução tampão $\mathrm{pH} 4$ e pH 7. O teor de sólidos solúveis (SS) $\left({ }^{\circ}\right.$ Brix) foi obtido por leitura direta de refratômetro portátil.

A determinação da acidez titulável (AT) foi realizada pelo método titulométrico. As bagas foram maceradas em um almofariz, retirando-se $1 \mathrm{~mL}$ de suco, no qual se adicionou $50 \mathrm{~mL}$ de água destilada e três gotas do indicador fenolftaleína, procedendo-se em seguida à titulação de $\mathrm{NaOH} 0,1 \mathrm{~N}$ previamente padronizada com bifitalato de potássio até ocorrer a viragem, ou seja, no momento que atingia $\mathrm{pH} 8,1$.

$\mathrm{O}$ experimento foi instalado em parcelas subdivididas, tendo nas parcelas três níveis de doses de nitrogênio aplicadas via fertirrigação $(35,70$ e $140 \mathrm{~g}$ planta $^{-1}$ de N) e nas subparcelas quatro níveis de manejos de irrigação (M1; M2, M3 e M4), no delineamento inteiramente casualizado com seis repetições. A parcela era constituída por uma planta. Os dados foram interpretados com base na análise de variância e as médias foram comparadas utilizando-se o teste de Tukey a 5\% de probabilidade.

\section{RESULTADOS E DISCUSSÃO}

Durante o período do experimento, a temperatura média do ar foi de $29^{\circ} \mathrm{C}$ e, segundo SENTELHAS (1998), a temperatura ótima para o desenvolvimento da videira é entre 15 e $30^{\circ} \mathrm{C}$, mas é possível ter um plantio de uva em regiões com temperatura entre $10 \mathrm{e} 40^{\circ} \mathrm{C}$. A evapotranspiração pluvial média dos meses de maio, junho, julho, agosto, setembro até o dia 06 de outubro de 2009 (data em que foi realizada a colheita) foi de 3,$2 ; 2,7 ; 3,3 ; 3,3 ; 4,3$ e $3,4 \mathrm{~mm} \mathrm{dia}^{-1}$. A produtividade média foi de 6,7 toneladas ha-1 ${ }^{-1}$.

As interações entre níveis de $\mathrm{N}$ e manejo da irrigação sobre o teor de sólidos solúveis, expressos 
em ${ }^{\circ}$ Brix estão apresentadas nas figuras 1A e 1B. Houve diferença significativa ao nível de 5\% de probabilidade pelo teste F da Análise de Variância, para a interação níveis de $\mathrm{N} x$ manejo da irrigação sobre o teor de sólidos solúveis, com coeficiente de variação de 3,6\%. Analisando-se o comportamento das estratégias de manejo da irrigação dentro de cada dose de $\mathrm{N}$ aplicada (Figura 1A), observa-se que os maiores valores de ${ }^{\circ}$ Brix encontrados ocorreram nas plantas que sofreram déficit hídrico de 33\% da lâmina e restrição total (0\%), após a fase de veraison, nas doses de $35 \mathrm{e} 70 \mathrm{~g}$ planta $^{-1}$. Para a dose de $140 \mathrm{~g}_{\text {planta }}{ }^{-1}$, observou-se o maior valor de ${ }^{\circ}$ Brix nas plantas sob restrição hídrica (sem irrigação), seguidas das plantas irrigadas com 33\%. Esses resultados estão de acordo com os encontrados por SILVA et al. (2009) que concluíram em sua pesquisa que a irrigação provoca alterações nas características químicas da uva, reduzindo seus valores, não sendo recomendado seu uso no período de maturação dos frutos, ou seja, nos meses próximos à colheita. No Submédio do Vale do São Francisco, BASSOI et al. (1999) também avaliaram a suspensão da irrigação na cultivar 'Itália', num período de até 30 dias antes da colheita, e não constataram redução significativa na qualidade ou na produtividade da uva. Os sólidos solúveis tendem a aumentar acentuadamente com o crescimento da baga até alcançar um ponto de equilíbrio, com valores que dependem da cultivar, tamanho da baga, produção por planta e das condições climáticas durante a maturação da baga. $\mathrm{O}$ teor de sólidos solúveis tende a aumentar com a maturação da baga, em consequência da degradação dos polissacarídeos e do conteúdo de água no solo. Segundo MARINHO et al. (2009), a redução da lâmina de irrigação, na fase de maturação da uva 'Superior Seedless', beneficia a qualidade da uva produzida no
Submédio do Vale do São Francisco, o que pode indicar uma estratégia de manejo a ser adotada pelo produtor para economizar água, sem impactos negativos nos sólidos solúveis. Resultados semelhantes foram encontrados por SHELLIE et al. (2006) em dois anos de produção (2003 e 2004).

Analisando-se conjuntamente as doses de $\mathrm{N}$ para as estratégias de manejo da irrigação (Figura 1B), observa-se que em todas as estratégias de manejo as doses de $70 \mathrm{e} 140 \mathrm{~g}$ planta $^{-1}$ apresentaram os maiores valores de ${ }^{\circ}$ Brix, com exceção do manejo de $33 \%$, no qual não houve efeito significativo entre as doses de $\mathrm{N}$ aplicadas. BRUNETTO et al. (2009), trabalhando com a uva 'Cabernet Sauvignon', no Município de Bento Gonçalves (RS), observaram que a aplicação de doses de $\mathrm{N}$ aumentou de forma linear os valores de sólidos solúveis ( ${ }^{\circ}$ Brix) e $\mathrm{pH}$ das bagas.

Nos municípios produtores de uva do Espírito Santo, a cultivar 'Niágara Rosada' geralmente é colhida com teores de SS ente 13 e $15^{\circ}$ Brix. Partindo dessa premissa, observa-se que a uva colhida no experimento, sob a dose de $\mathrm{N}$ de $70 \mathrm{~g} \mathrm{planta}^{-1}$ e com restrição hídrica após a fase de veraison, representa a melhor combinação para se obter altos teores de SS, expressos em ${ }^{\circ} \mathrm{Brix}$, característica mais apreciada pelos consumidores de uva para mesa. O teor de SS pode ser considerado muito bom, com média superior a $16^{\circ} \mathrm{Brix}$, ficando acima do recomendado pelas normas internacionais de comercialização, sendo adotada no Vale do São Francisco, cujos valores mínimos são $15^{\circ}$ Brix (SOARES \& LEÃO, 2009).

Observou-se que houve diferença significativa no valor médio de $\mathrm{pH}$ das bagas da videira 'Niágara Rosada' em função das doses de N, não ocorrendo efeito estatístico do manejo da irrigação e da interação dose e manejo (Figura 2), com coeficiente

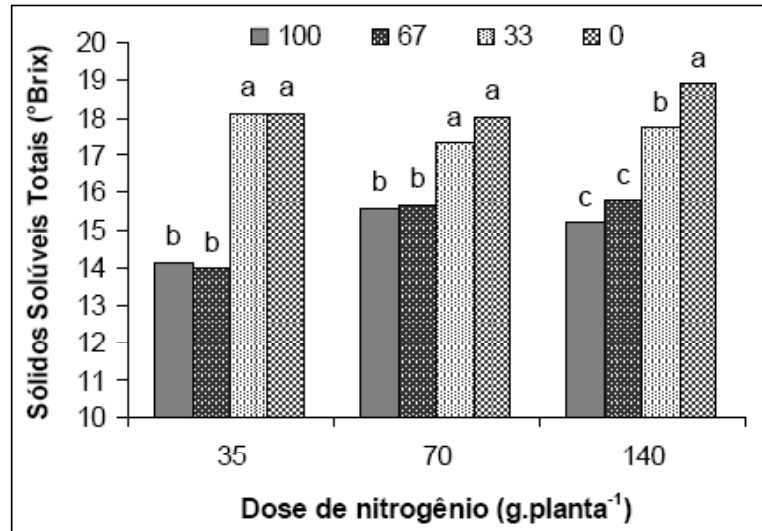

A

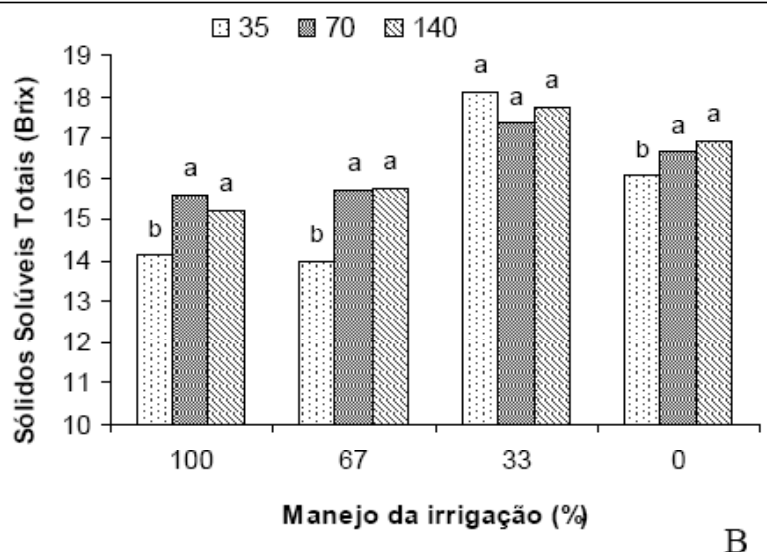

B

Figura 1 - Sólidos solúveis ( ${ }^{\circ}$ Brix) em função das doses de $\mathrm{N}$ aplicadas por planta da uva cultivar 'Niágara Rosada', para as estratégias de manejo da irrigação (A); e em função das estratégias de manejo da irrigação para cada dose de $\mathrm{N}$ estudada (B). Colatina, ES. 2009.

*Valores não seguidos de mesma letra diferem entre si em nível de $5 \%$ de probabilidade pelo teste de Tukey. 


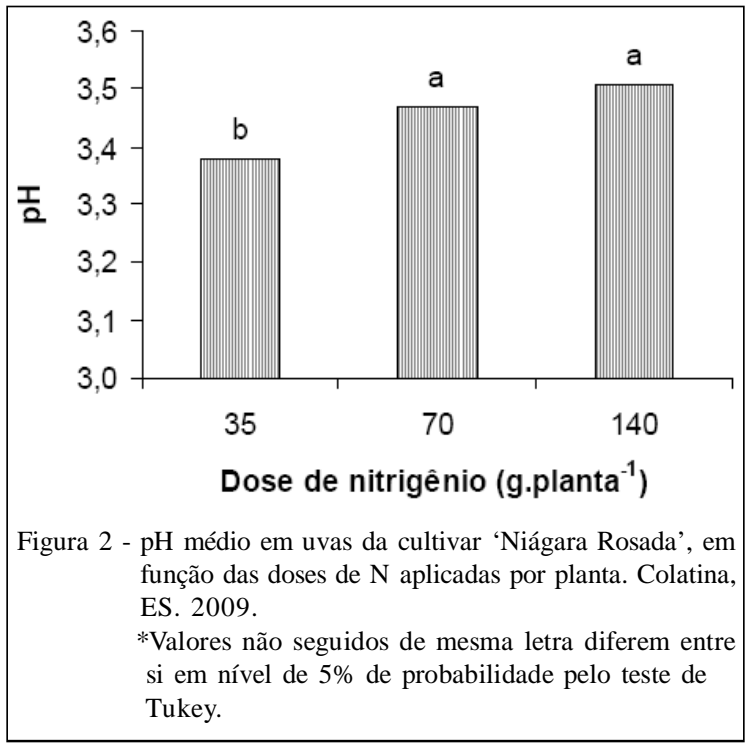

de variação de $1,7 \%$. Nota-se que as doses de 70 e $140 \mathrm{~g}$ planta $^{-1}$ apresentaram os maiores valores de $\mathrm{pH}$ em relação à dose de $35 \mathrm{~g}$ planta $^{-1}$, com valores de $\mathrm{pH}$ de 3,38; 3,47 e 3,50, respectivamente, para as doses de 35,70 e 140 g planta $^{-1}$ de N.

Em relação à acidez titulável (AT), expressa em $\mathrm{g} \mathrm{L}^{-1}$, das bagas da cultivar 'Niágara Rosada', em função das doses de $\mathrm{N}$ e estratégias de manejo da irrigação, verifica-se que houve efeito significativo da interação dose e manejo, com coeficiente de variação de 6\%. Analisando as estratégias de manejo da irrigação para cada dose de $\mathrm{N}$ aplicada, conforme a figura $3 \mathrm{~A}$, observa-se que as plantas cultivadas na parcela sob 35 planta $^{-1}$ de $\mathrm{N}$ responderam de forma diferente quanto ao manejo da irrigação. A acidez diminuiu com o aumento da restrição hídrica nesta dose, sendo que os manejos de 100 e $67 \%$ apresentaram maior AT, estatisticamente, em relação aos manejos de 33 e $0 \%$. Para a parcela de $70 \mathrm{~g}$ planta $^{-1}$ de $\mathrm{N}$, não houve diferença significativa de acidez para as estratégias de manejo estudadas. Esses resultados corroboram os obtidos por SANTOS \& KAYE (2009), na região sul de Fresno, no vale de San Joaquin (EUA), para a videira 'Syrah', que obtiveram menor AT nas bagas de plantas sob baixo estresse hídrico. MARINHO et al. (2009) concluíram em sua pesquisa, no Município de Casa Nova-BA, que, quanto maior o déficit de irrigação e a sua duração, maior a redução de acidez titulável na uva 'Superior Seedless'. Redução aparente de AT também foi observada em videiras 'Merlot' submetidas a déficit de irrigação, no sudeste de Idaho (SHELLIE et al., 2006). Essa redução da acidez titulável, associada ao déficit hídrico, pode ser atribuída à redução de malato (ESTEBAN et al., 1999).

$\mathrm{Na}$ figura 3B, têm-se as diferenças significativas para as doses de $\mathrm{N}$ dentro de cada nível de manejo da irrigação. Da mesma forma, as plantas mostraram respostas distintas no estudo das doses de $\mathrm{N}$ em função dos manejos da irrigação, mas também se observaram maiores valores de acidez nos níveis que receberam a dose de $35 \mathrm{~g}_{\text {planta }^{-1}}$. Para o manejo de $33 \%$, não houve diferença significativa.

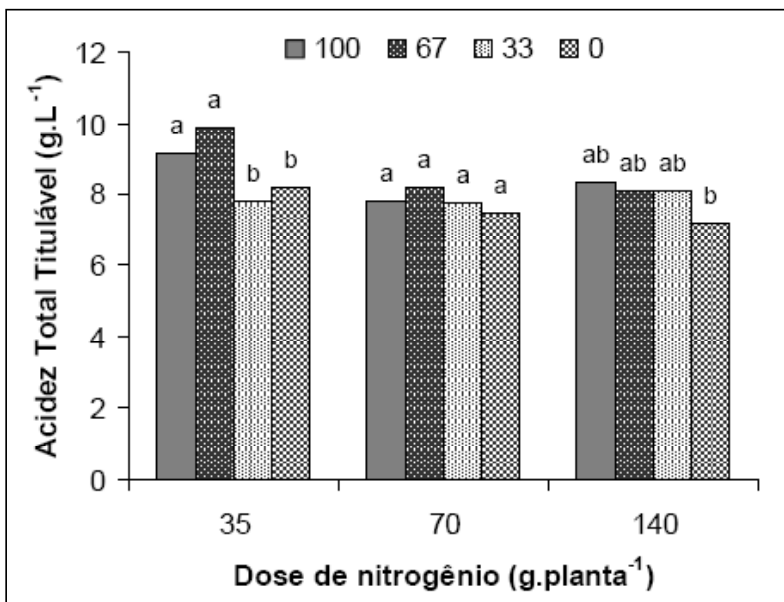

A

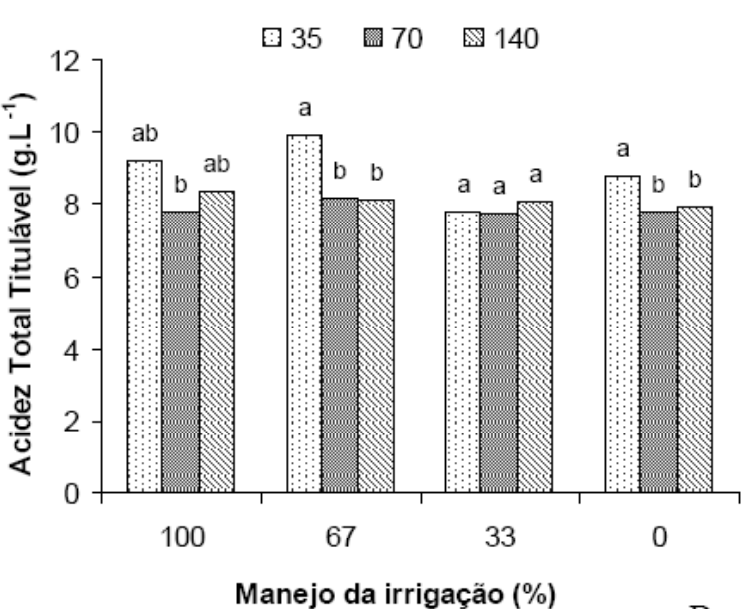

B

Figura 3 - Acidez titulável $\left(\mathrm{g} \mathrm{L}^{-1}\right)$ em função das doses de $\mathrm{N}$ aplicadas por planta da uva cultivar 'Niágara Rosada', para as estratégias de manejo da irrigação (A); e em função das estratégias de manejo da irrigação para cada dose de $\mathrm{N}$ estudada (B). Colatina, ES. 2009.

*Valores não seguidos de mesma letra diferem entre si em nível de 5\% de probabilidade pelo teste de Tukey. 


\section{CONCLUSÃO}

A aplicação de nitrogênio afeta as características químicas da baga da videira 'Niágara Rosada', aumentando os valores de sólidos solúveis e $\mathrm{pH}$, e diminuindo a acidez titulável. As estratégias de manejo da irrigação diferenciaram os valores de sólidos solúveis e acidez titulável, mas não apresentaram influência sobre o pH das bagas.

\section{REFERÊNCIAS}

BASSOI, L.H.; et al. Interrupção da irrigação no período de maturação da uva cv. Itália. Petrolina: Embrapa-CPATSA, 1999. 5p. (Comunicado técnico, 79).

BELL, S.J.; ROBSON, A. Effect of nitrogen fertilization on growth, canopy density, and yield of Vitis viniferas L. cv. 'Cabernet Sauvignon'. American Journal of Enology and Viticulture, v.50, p.351-358, 1999.

BERNARDO, S. et al. Manual de irrigação. 8.ed. Viçosa: UFV, 2008. 625p.

BRUNETTO, G. et al. Produção e composição química da uva de videiras Cabernet Sauvignon submetidas à adubação nitrogenada. Ciência Rural, v.39, n.7, p.2035-2041, 2009. Disponível em: $<$ http://www.scielo.br/scielo.php?script=sci_abstract\&pid=S0103$84782009000700013 \& \operatorname{lng}=p t \& n r m=i s o \&$ tlng $=p t>$. Acesso em: 02 jul. 2010 . doi: 10.1590/S0103-84782009005000162.

EMPRESA BRASILEIRA DE PESQUISA AGROPECUARIA. Sistema Brasileiro de Classificação de Solos. Editores técnicos, Humberto Gonçalves dos Santos et al. 2.ed. Rio de Janeiro: EMBRAPA SOLOS, 2006. 306p.

ESTEBAN, M.A. et al. Effect of irrigation on changes in berry composition of Tempranillo during maturation. Sugars, organic acids, and mineral elements. American Journal of Enology and Viticulture, v.50, p.418-434, 1999.

FERREYRA R.E. et al. Effect of water stress applied at different development periods of Cabernet Sauvignon grapevine on production and wine quality. Acta Horticulturae, v.646, p.2733,2004

MARINHO, L.B. et al. Produção e qualidade da videira 'Superior Seedless' sob restrição hídrica na fase de maturação. Pesquisa Agropecuária Brasileira, v.44, n.12, p.1682-1691, 2009.

SANTOS, A.O.; KAYE, O. Composição quali-quantitativa da produção de 'Syrah' cultivada sob estresse hídrico transiente. Revista Brasileira de Engenharia Agrícola e Ambiental, v.13, n.3, p.272-281, 2009.

SENTELHAS, P.C. Aspectos climáticos para a viticultura tropical. Informe Agropecuário, v.19, n.194, p.9-14, 1998.

SHELLIE, K.C. Vine and berry response of Merlot (Vitis vinifera L.) to differential water stress. American Journal of Enology and Viticulture, v.57, p.514-518, 2006

SILVA, R.J.L. et al. Efeito da poda antecipada e regime de irrigação nos teores de açúcares em uvas 'Niágara Rosada'. Ciência e Agrotecnologia, v.33, n.3, p.844-847, 2009.

SOARES, J.M.; LEÃO, P.C. de S. A vitivinicultura no Semiárido brasileiro. Brasília, DF: Embrapa Informação Tecnológica; Petrolina: Embrapa Semi-Árido, 2009. 756p.

SÔNEGO, O.R. et al. Doenças e pragas. In: MAIA, J.D.G.; KUHN, G.B. Cultivo da Niágara Rosada em áreas tropicais do Brasil. Bento Gonçalves, RS: Embrapa Uva e Vinho, 2004. p.1-77.

TEIXEIRA, A.H.C. et al. Aptidão agroclimática da cultura da videira no Estado da Bahia. Revista Brasileira de Engenharia Agrícola e Ambiental, v.6, n.1, p.107-111, 2002. 